\title{
LIXIVIAÇÃO ÁCIDA DE BATERIAS ÍON-LÍTIO
}

\author{
Rafael Gundim Silva ${ }^{a}$, Júlio Carlos Afonso ${ }^{\mathrm{b}, *}$ e Claudio Fernando Mahler ${ }^{\mathrm{a}}$ \\ a'Departamento de Química Analítica, Instituto de Química, Universidade Federal do Rio de Janeiro, 21941-909 Rio de Janeiro \\ - RJ, Brasil \\ 'Instituto Alberto Luiz Coimbra de Pós-Graduação e Pesquisa em Engenharia, Universidade Federal do Rio de Janeiro, 21941-596 \\ Rio de Janeiro - RJ, Brasil
}

Recebido em 28/11/2017; aceito em 06/02/2018; publicado na web em 22/02/2018

\begin{abstract}
ACIDIC LEACHING OF Li-ION BATTERIES. This paper describes a route for recovering cobalt and lithium from spent Li-ion batteries via acidic leaching. Sulfuric, hydrochloric, hydrofluoric and formic acids were used as leachants. Hydrogen peroxide was added as reductant, except for formic acid since it is itself a reductant. Experiments were run at $25-40{ }^{\circ} \mathrm{C}$ for $1-3 \mathrm{~h}$. Under the best optimal conditions, the leaching efficiency order was $\mathrm{HCl} \approx \mathrm{HF}>\mathrm{H}_{2} \mathrm{SO}_{4}>\mathrm{HCOOH}$. Over $90 \mathrm{wt}$ \% of cobalt and lithium were leached by the inorganic acids. The insoluble matter corresponds mainly to the carbon from the cathode. Co(II) was extracted with D2EHPA $16 \mathrm{vol} . \%$ diluted in $\mathrm{n}$-hexane at $\mathrm{pH} \sim 5$ (A/O ratio $1 / 1 \mathrm{vol} / \mathrm{vol}$, one stage, $25^{\circ} \mathrm{C}$ ). $\mathrm{Co}$ (II) striping was possible using a dilute leachant (1-2 $\mathrm{mol} \mathrm{L}^{-1} \mathrm{HCl}$ or $\mathrm{H}_{2} \mathrm{SO}_{4}, 4-5 \mathrm{~mol} \mathrm{~L}{ }^{-1} \mathrm{HF}$ or $\mathrm{HCOOH}$ ). Lithium was isolated from the raffinate by precipitation as carbonate or phosphate.
\end{abstract}

Keywords: lithium-ion battery; metals recovery; solvent extraction; cobalt; lithium.

\section{INTRODUÇÃO}

As baterias de íon-lítio por apresentarem uma elevada densidade de energia, vida útil longa, massa reduzida, taxa de descarga baixa e menor toxicidade em relação a outros tipos de baterias (níquel-cádmio, níquel hidreto metálico), são hoje muito utilizadas em telefones celulares, câmeras fotográficas e outros equipamentos eletroeletrônicos (EEE) portáteis. ${ }^{1,2} \mathrm{O}$ desenvolvimento de novas versões tecnológicas desses equipamentos e a maior facilidade de acesso dos mesmos a mais camadas da população levam a uma inevitável elevação da produção e do consumo de EEE e, consequentemente, de suas baterias. Mais de $60 \%$ do mercado da energia potátil é hoje preenchido por baterias de íon-lítio. ${ }^{3-6}$ Suas características o colocam na dianteira do desenvolvimento de veículos híbridos e elétricos. ${ }^{6-8}$

Essas baterias apresentam em sua composição um ânodo, um cátodo, coletores de corrente, um separador, um eletrólito, um invólucro externo e peças de vedação. O ânodo é composto de grafite, lítio, carbono e fluoreto de polivinilideno (PVDF), que fixa os demais componentes ao coletor de corrente, que é uma lâmina de cobre; o eletrólito é tipicamente hexafluorfosfato de lítio $\left(\mathrm{LiPF}_{6}\right)$ em solvente orgânico, normalmente carbonato de etileno (CE), carbonato de dietila (DEC), carbonato de dimetila (DMC) ou misturas deles. O separador é feito de polipropileno (PP) ou polietileno (PE). O cátodo é feito de carbono (grafita), um óxido misto contendo lítio e cobalto (como o $\mathrm{LiCoO}_{2}$, que detém $40 \%$ do mercado $^{6}$ ) e PVDF, que fixa os componentes ao coletor de corrente do cátodo, que é uma lâmina de alumínio. Hoje, cerca de $25 \%$ do cobalto produzido no mundo se destina à manufatura de baterias. ${ }^{8} \mathrm{~A}$ expansão do mercado de EEE portáteis pressiona o preço desse metal nos mercados internacionais. ${ }^{9,10}$ Além disso, devido a problemas relacionados à disponibilidade de cobalto (as principais fontes primárias se localizam em regiões de forte instabilidade geopolítica) e ainda para permitir uma operção mais segura em temperaturas mais elevadas que a ambiente, parte desse elemento no óxido misto do catodo vem sendo substituída por outros metais mais baratos (níquel, ferro, manganês). ${ }^{6,8,11,12}$

\footnotetext{
*e-mail: julio@iq.ufrj.br
}

Em contrapartida ao consumo crescente, grandes quantidades de resíduos de EEE vêm sendo produzidas devido à obsolescência (perceptiva e programada). Segundo a GSMA (Group Managed Service Accounts) da UNU (United Nations University), ${ }^{13}$ aproximadamente 189 mil $\mathrm{t}$ de telefones celulares foram descartados em todo o mundo em 2014, dos quais cerca de 17 mil t na América Latina. O total de lixo eletrônico produzido em 2014 no mundo foi de 3.904 mil t. Isto significa que a fração correspondente a telefones celulares representa menos de $5 \%$ da massa total do lixo eletrônico produzido em todo o mundo. Apesar disso, as baterias presentes nesses aparelhos são um sério problema ambiental se descartadas de forma inadequada, pois apresentam concentrações elevadas de metais perigosos além de eletrólitos. ${ }^{13}$ Por outro lado, tais baterias contêm teores consideráveis de metais de alto valor agregado (lítio, cobalto e mesmo outros como cobre, níquel e manganês), frequentemente superando aqueles existentes em fontes primárias. . $^{1,-8,12}$

A reciclagem de baterias de íon-lítio é uma solução tanto para eliminar os riscos ambientais decorrentes de seu descarte inadequado como para recuperar seus componentes de valor agregado. Porém, as rotas de processamento desenvolvidas até o presente momento possuem entraves como elevado consumo energético, emprego de reagentes tóxicos e/ou corrosivos, geração de grande quantidade de resíduos finais e recuperação apenas moderada de metais como cobalto e lítio. . $2,9,14-16^{-16}$

A maior parte dos processos descritos na literatura envolve lixiviação dos componentes eletroativos (catodo, anodo e eletrólito) por um meio ácido contendo um agente redutor para permitir a redução de Co(III) a Co(II), estável e solúvel em meio aquoso ácido. O meio ácido normalmente é inorgânico forte (principalmente $\mathrm{H}_{2} \mathrm{SO}_{4}$ ), ${ }^{7,8,17,18}$ mas ácidos orgânicos vem sendo igualmente testados por suas propriedades complexantes em um meio menos corrosivo. ${ }^{7,11,16} \mathrm{O}$ redutor é, frequentemente, $\mathrm{H}_{2} \mathrm{O}_{2}$. Outros redutores como sulfitos, ozônio e carboidratos também vêm sendo testados. ${ }^{7,16}$

Aparentemente não há menção ao uso de ácido fluorídrico. O íon fluoreto é uma base muito forte e forma complexos muito estáveis com cátions contendo configurações de gás nobre (os ácidos duros) como $\mathrm{Al}^{3+} \mathrm{e} \mathrm{Fe}^{3+} \cdot{ }^{19,20}$ Esse ânion também pode precipitar certos cátions 
(como $\mathrm{Li}^{+}, \mathrm{Mg}^{2+} \mathrm{e} \mathrm{Ca}^{2+}$ ) que não são normalmente precipitados pelos ácidos usuais. Essas propriedades são relevantes na medida em que a etapa de separação dos elementos lixiviados é impactada. Esse ácido já foi testado com sucesso no processamento hidrometalúrgico de catalisadores e pilhas $\mathrm{Zn}-\mathrm{MnO}_{2}{ }^{21-23}$

Ao contrário de diversos ácidos carboxílicos usados como complexantes (cítrico, málico, succínico, tartárico, oxálico), ${ }^{2,16} \mathrm{o}$ ácido fórmico parece não ter sido testado. Tal como o ácido oxálico, o mais simples dos ácidos monocarboxílicos alifáticos é um poderoso agente redutor, mas não precipita íons metálicos como no caso do oxalato. ${ }^{19,20}$ Dessa forma, esse ácido pode desempenhar um duplo papel, como lixiviante e redutor. ${ }^{23}$ Sua decomposição em presença de ar ou oxidantes $\left(\mathrm{CO}_{2}+\mathrm{H}_{2} \mathrm{O}\right)$ não produz resíduos. Ele já foi reconhecido como um reagente versátil e renovável para sínteses e processos químicos. ${ }^{24}$

$\mathrm{O}$ cobalto é frequentemente isolado por precipitação, por exemplo, como oxalato $\left(\mathrm{CoC}_{2} \mathrm{O}_{4}\right)$, eletrodeposição ou extração líquido-líquido. ${ }^{10,16,17}$ Dada a possibilidade da presença de manganês e/ou níquel no óxido misto com lítio, esta última técnica se revela particularmente eficaz. O ácido bis-2-etil-hexilfosfórico (D2EHPA) serve para separar manganês de cobalto em $\mathrm{pH} \sim 3.5$ em meio de ácido sulfúrico. ${ }^{10}$ Este mesmo extratante pode separar cobalto de níquel em meio sulfúrico ou clorídrico de menor acidez. ${ }^{25}$ PC88A (hidrogeno 2-etil-hexilfosfonato de 2-etil-hexila) e Cyanex 272 (ácido bis-2,4,4-trimetilpentilfosfínico) são também usados para isolamento do cobalto em meio ácido (clorídrico/sulfúrico). ${ }^{10,12}$

Neste trabalho foi investigada a eficiência da utilização de meio ácido fraco (fluorídrico, fórmico) comparado a um de ácido forte (sulfúrico, clorídrico) na presença de um agente redutor (peróxido de hidrogênio, exceto no caso do ácido fórmico, pois ele também é agente redutor) no processamento dos componentes eletroativos (catodo, anodo e eletrólito) de baterias íon-lítio oriundas de aparelhos celulares, sob condições experimentais brandas. O emprego de ácidos fracos (mas com propriedades complexantes ou redutoras) é uma novidade em relação aos processos relatados na literatura, normalmente baseados em ácidos inorgânicos fortes. O lixiviado, após separação do resíduo insolúvel, foi submetido a procedimento de extração líquido-líquido para a recuperação do cobalto e de precipitação para o lítio.

\section{PARTE EXPERIMENTAL}

\section{Materiais}

Foram utilizadas neste estudo 50 baterias de íon-lítio empregadas em telefones celulares de três fabricantes distintos, produzidos entre 2010 e 2014. As baterias foram descarregadas e colocadas em uma câmara de refrigeração a $5{ }^{\circ} \mathrm{C}$. Após esse procedimento, as baterias foram abertas manualmente em uma capela sob exaustão. A blindagem de aço foi retirada e colocada em sistema de vácuo por 20 min para remoção e condensação do solvente não aquoso presente. Após esse procedimento, procedeu-se à separação do catodo e do anodo das lâminas, realizada por vibração mecânica e raspagem cuidadosa do pó. As massas dos componentes eletroativos combinados (catodo, anodo e eletrólito) foram determinadas por meio de uma balança analítica. A Figura 1 ilustra a massa de componentes eletroativos após eliminação do solvente e separação manual.

\section{Lixiviação ácida}

Os procedimentos foram realizados em batelada em béqueres de teflon providos de agitador magnético. A razão volume de solução/

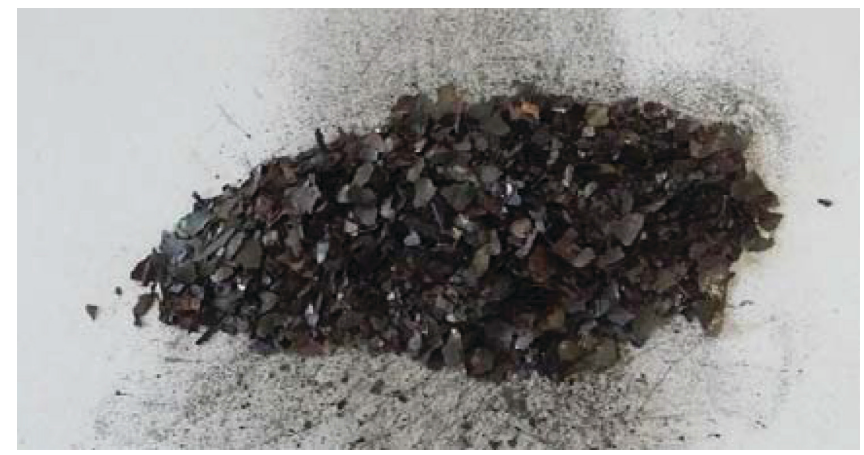

Figura 1. Componentes eletroativos isolados após eliminação do solvente não aquoso e raspagem manual

massa de componentes eletroativos $\left(\mathrm{mL} \mathrm{g}^{-1}\right)$ foi fixada em 10 . As lixiviações foram realizadas com um dos ácidos a seguir: $\mathrm{H}_{2} \mathrm{SO}_{4}$, $(49 \% \mathrm{~m} / \mathrm{m}, \sim 9 \mathrm{~mol} \mathrm{~L}-1) \mathrm{HCl}\left(37 \% \mathrm{~m} / \mathrm{m}, \sim 12 \mathrm{~mol} \mathrm{~L}^{-1}\right)$, $\mathrm{HF}(40 \%$ $\left.\mathrm{m} / \mathrm{m}, \sim 20 \mathrm{~mol} \mathrm{~L}^{-1}\right)$ e $\mathrm{HCOOH}\left(88 \% \mathrm{~m} / \mathrm{m}, \sim 20 \mathrm{~mol} \mathrm{~L}^{-1}\right)$, todos pro analisi, e usados sem purificação adicional. Os ácidos foram diluídos com igual volume de $\mathrm{H}_{2} \mathrm{O}_{2} 30 \% \mathrm{~m} / \mathrm{m}\left(\sim 10 \mathrm{~mol} \mathrm{~L}^{-1}\right)$. No caso do ácido fórmico, também agente redutor, a diluição foi feita com água destilada. $\mathrm{O}$ manuseio dos ácidos (especialmente $\mathrm{HF}$ ) e do $\mathrm{H}_{2} \mathrm{O}_{2}$ foi realizado usando equipamentos de proteção pessoal adequados em uma capela com exaustão.

A temperatura inicial foi $25^{\circ} \mathrm{C}$. Após a adição da massa de componentes eletroativos, a temperatura aumentou $10-15^{\circ} \mathrm{C}$ após cerca de $1 \mathrm{~h}$ na presença de $\mathrm{H}_{2} \mathrm{O}_{2}$. A temperatura diminuiu para $28-30{ }^{\circ} \mathrm{C}$ ao final dos experimentos. Nenhum efeito térmico foi observado quando o ácido fórmico foi o lixiviante. Nesse caso, seus experimentos foram paulatinamente aquecidos em placa agitadora-aquecedora durante 1 $\mathrm{h}$ até $\sim 40^{\circ} \mathrm{C}$, após o que a temperatura foi reduzida gradativamente para $\sim 30^{\circ} \mathrm{C}$ ao final da experiência.

As seguintes equações descrevem as reações propostas envolvendo o cobalto e o lítio, com valores de $\Delta \mathrm{G}^{0}$ a $30{ }^{\circ} \mathrm{C}(303 \mathrm{~K}):^{26}$

$$
\begin{array}{r}
2 \mathrm{LiCoO}_{2}+\mathrm{H}_{2} \mathrm{O}_{2}+6 \mathrm{HF} \rightarrow 2 \mathrm{CoF}_{2}+2 \mathrm{LiF}+4 \mathrm{H}_{2} \mathrm{O}+\mathrm{O}_{2} \\
\Delta \mathrm{G}^{0}=-221.9 \mathrm{~kJ} \\
2 \mathrm{LiCoO}_{2}+\mathrm{H}_{2} \mathrm{O}_{2}+6 \mathrm{HCl} \rightarrow 2 \mathrm{CoCl}_{2}+2 \mathrm{LiCl}+4 \mathrm{H}_{2} \mathrm{O}+\mathrm{O}_{2} \\
\Delta \mathrm{G}^{0}=-221.9 \mathrm{~kJ} \\
\\
2 \mathrm{LiCoO}_{2}+\mathrm{H}_{2} \mathrm{O}_{2}+3 \mathrm{H}_{2} \mathrm{SO}_{4} \rightarrow 2 \mathrm{CoSO}_{4}+\mathrm{Li}_{2} \mathrm{SO}_{4}+4 \mathrm{H}_{2} \mathrm{O}+\mathrm{O}_{2} \\
\Delta \mathrm{G}^{0}=-221.9 \mathrm{~kJ}
\end{array}
$$

$$
\begin{array}{r}
2 \mathrm{LiCoO}_{2}+7 \mathrm{HCOOH} \rightarrow 2 \mathrm{Co}(\mathrm{HCOO})_{2}+2 \mathrm{HCOOLi}+4 \mathrm{H}_{2} \mathrm{O}+\mathrm{CO}_{2} \\
\Delta \mathrm{G}^{0}=-391.7 \mathrm{~kJ} \\
2 \mathrm{Li}+2 \mathrm{H}_{3} \mathrm{O}^{+} \rightarrow 2 \mathrm{Li}^{+}+2 \mathrm{H}_{2} \mathrm{O}+\mathrm{H}_{2} \quad \Delta \mathrm{G}^{0}=-140,0 \mathrm{~kJ}
\end{array}
$$

Todos os valores de $\Delta \mathrm{G}^{0}$ são negativos. Segue-se que as reações ocorrem com elevada probabilidade na direção dos produtos previstos na faixa de temperatura deste trabalho. As reações 2, 3 e 5 já foram constatadas em diversos trabalhos da literatura. ${ }^{2,3,7,18}$

O tempo da reação foi variado (1-3 h). A agitação foi fixada em $200 \mathrm{rpm}$. A massa insolúvel foi separada do lixiviado por filtração sob vácuo. Depois de lavada com água destilada até teste negativo para $\mathrm{Co}(\mathrm{II})^{19,20}\left(10 \mathrm{~mL} \mathrm{~g}^{-1}\right)$, ela foi seca em estufa a $150{ }^{\circ} \mathrm{C}$ por $3 \mathrm{~h}$, resfriada em dessecador, pesada em balança analítica e calcinada em mufla sob fluxo de ar a $600{ }^{\circ} \mathrm{C}$ por $5 \mathrm{~h}$ para eliminação de carbono e demais componentes voláteis. A cinza foi resfriada na própria mufla e depois pesada. A reprodutibilidade da lixiviação foi determinada como sendo cerca de $\pm 4 \%$. 


\section{Procedimentos para extração líquido-líquido do Co(II)}

Todos os experimentos foram conduzidos (em triplicata) a $25^{\circ} \mathrm{C}$. A razão entre as fases aquosa (lixiviado) e orgânica (A/O) foi estabelecida em 1 vol/vol. Ácido bis-2-etil-hexilfosfórico (D2EHPA) foi empregado como extratante para $\mathrm{Co}(\mathrm{II})$. A concentração variou de 3 a $25 \%$ vol. e o diluente foi o n-hexano. $\mathrm{O} \mathrm{pH}$ do lixiviado foi ajustado mediante adição de $\mathrm{NaOH} 6 \mathrm{~mol} \mathrm{~L}^{-1}$. O sistema foi agitado por 10 min e depois deixado em repouso para a separação das fases. Um aspecto da fase orgânica após a extração do cobalto é visto na Figura 2. A forte coloração azul da fase orgânica facilita o controle visual e o andamento da extração do Co(II).

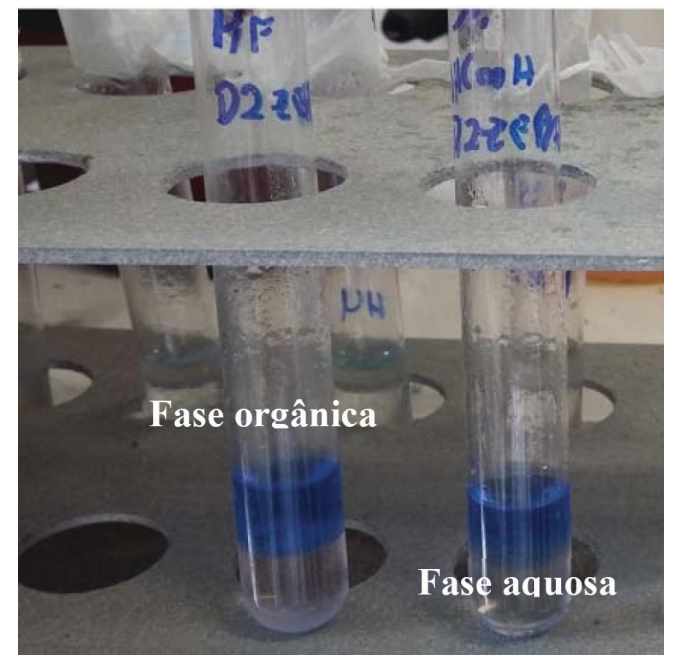

Figura 2. Extração do Co(II) por D2EHPA 6\% vol. em querosene. A cor azul corresponde a íons $\mathrm{Co}^{2+}$ sem água em sua esfera de coordenação

A eficiência da extração pode ser calculada com base na concentração de $\mathrm{Co}$ (II) no lixiviado e no rafinado (supondo que não haja contração ou expansão dessa fase líquida), conforme a equação (6):

$$
\mathrm{E}=\left(1-\left(\mathrm{C}_{1}-\mathrm{C}_{2} / \mathrm{C}_{1}\right)\right) \times 100
$$

em que E é a eficiência de lixiviação, $\mathrm{C}_{1}$ é a concentração do metal no lixiviado, e $\mathrm{C}_{2}$ é a concentração do metal no rafinado. ${ }^{27}$

A remoção do cobalto da fase orgânica foi ensaiada com o mesmo ácido da lixívia correspondente em concentrações variadas. As condições experimentais foram as mesmas aplicadas ao processo de extração do metal do lixiviado.

\section{Isolamento do lítio}

Ao rafinado, incolor, ajustou-se o $\mathrm{pH}$ em $\sim 7$ mediante adição de solução de $\mathrm{NaOH} 6 \mathrm{~mol} \mathrm{~L}^{-1}$. Formou-se um precipitado gelatinoso esverdeado, que foi filtrado sob vácuo. Ao filtrado foi adicionada uma solução de um ânion precipitante do cátion $\mathrm{Li}^{+}: \mathrm{Na}_{2} \mathrm{CO}_{3}\left(3 \mathrm{~mol} \mathrm{~L} \mathrm{~L}^{-1}\right)$ ou $\mathrm{K}_{3} \mathrm{PO}_{4}\left(1 \mathrm{~mol} \mathrm{~L} \mathrm{~L}^{-1}\right)$. A adição foi feita gota a gota, sob agitação (200 rpm), à temperatura ambiente $\left(\mathrm{K}_{3} \mathrm{PO}_{4}\right)$ ou a temperaturas próximas de $100^{\circ} \mathrm{C}\left(\mathrm{Na}_{2} \mathrm{CO}_{3}\right)$, pois a solubilidade do sal $\mathrm{Li}_{2} \mathrm{CO}_{3}$ em água é mínima em temperaturas mais elevadas. ${ }^{19,27,28}$

$$
\begin{array}{ll}
2 \mathrm{Li}^{+}+\mathrm{CO}_{3}{ }^{2-} \longrightarrow \mathrm{Li}_{2} \mathrm{CO}_{3} \downarrow & \left(\mathrm{K}_{\mathrm{ps}}=4.0 \times 10^{-3}\right) \\
3 \mathrm{Li}^{+}+\mathrm{PO}_{4}{ }^{3-} \longrightarrow \mathrm{Li}_{3} \mathrm{PO}_{4} \downarrow & \left(\mathrm{K}_{\mathrm{ps}}=3.2 \times 10^{-9}\right)
\end{array}
$$

Os precipitados foram filtrados e lavados com solução diluída de carbonato de amônio $\left(0.01 \mathrm{~mol} \mathrm{~L}^{-1}\right)$ ou fosfato de amônio $\left(0.05 \mathrm{moL} \mathrm{L} \mathrm{L}^{-1}\right)$, secos a $150{ }^{\circ} \mathrm{C}$ por $3 \mathrm{~h}$ e pesados.

\section{Métodos analíticos}

As medidas de $\mathrm{pH}$ foram feitas com um eletrodo de vidro combinado a um eletrodo de referência $\mathrm{Ag} / \mathrm{AgCl}$ (Orion 2AI3-JG). Os metais em solução foram analisados por absorção atômica (Perkin Elmer AAS 3300). A técnica de fluorescência de raios-X (FRX) foi empregada no caso de amostras sólidas (RIGAKU K-1800, 20 mA e $40 \mathrm{kV}$ ). Curvas de calibração foram estabelecidas para cobre, níquel, alumínio, fósforo, cobalto e lítio, onde as concentrações das soluções-padrão variaram de 0,1 a $10 \mathrm{~g} \mathrm{~L}^{-1}$.

\section{RESULTADOS E DISCUSSÃO}

\section{Composição das baterias}

A Tabela 1 apresenta a composição media das baterias de íon-lítio estudadas. A massa eletroativa (anodo, catodo e eletrólito) corresponde a $40 \%$ da massa total da bateria. Os dados de FRX dessa massa assinalam a presença de cobalto (40\%) e lítio (12\%) como os metais mais abundantes. Isso fornece um teor médio de $16 \%$ $\mathrm{m} / \mathrm{m}$ de cobalto e $4.8 \% \mathrm{~m} / \mathrm{m}$ de lítio nas baterias em estudo. Outros elementos, identificados em pequenas quantidades, foram alumínio, cobre (ambos decorrentes da esfoliação das lâminas), cálcio, níquel e fósforo; este último sugere que o eletrólito é o hexafluorofosfato de lítio $\left(\mathrm{LiPF}_{6}\right)$. O solvente não aquoso condensado após remoção a vácuo representa aproximadamente $4,5 \% \mathrm{~m} / \mathrm{m}$ da composição da pilha. Os dados de composição apresentados estão de acordo com os valores relatados na literatura. . $^{10,16,28,29}$

Tabela 1. Composição media das baterias de íon-lítio

\begin{tabular}{lc}
\hline Componentes & Percentuais $(\mathrm{m} / \mathrm{m})$ \\
\hline Catodo + anodo + eletrólito* & $40,0 \%$ \\
Carcaça plástica externa & $23,0 \%$ \\
Blindagem de aço & $10,5 \%$ \\
Solvente não aquoso & $4,5 \%$ \\
Lâmina de cobre & $8,2 \%$ \\
Lâmina de alumínio & $6,1 \%$ \\
Separador polimérico & $5,1 \%$ \\
Contatos elétricos & $2,6 \%$ \\
\hline
\end{tabular}

*O carbono corresponde a $30-32 \% \mathrm{~m} / \mathrm{m}$ destes componentes $(12-13 \% \mathrm{~m} / \mathrm{m}$ da amostra total).

\section{Comportamento da lixiviação em presença de ácidos fortes e fracos}

Os dados da Tabela 2 indicam que os ácidos fluorídrico e clorídrico apresentaram eficiências similares, enquanto os resultados com o ácido sulfúrico foram superiores aos obtidos com ácido fórmico. Para todos eles, o aumento do tempo teve um efeito positivo na lixiviação até 3 h. A lixiviação dos componentes eletroativos das baterias de íon-lítio atingiu o equilíbrio em tempo comparável aos estudos com as pilhas $\mathrm{Zn}-\mathrm{MnO}_{2} \cdot{ }^{13}$

Os ácidos apresentaram o seguinte desempenho para a lixiviação do cobalto e do lítio: $\mathrm{HCl} \approx \mathrm{HF}>\mathrm{H}_{2} \mathrm{SO}_{4}>\mathrm{HCOOH}$. O desempenho dos ácidos fortes é comparável aos dados da literatura9,10,16 em condições experimentais similares àquelas deste trabalho. Quanto aos ácidos fracos, o fluorídrico teve eficiência comparável ao $\mathrm{HCl}$ quanto à lixiviação dos dois elementos. Porém, há uma ressalva no caso do lítio. O percentual alto de lixiviação desse metal nos lixiviados em presença de $\mathrm{HF}$ deve ser atribuído à solubilidade do $\mathrm{LiF}$ em presença 
Tabela 2. Lixiviação do cobalto e do lítio em função do ácido e do tempo

\begin{tabular}{|c|c|c|c|}
\hline Lixiviante & Tempo (h) & $\begin{array}{c}\text { Co lixiviado } \\
(\% \mathrm{~m} / \mathrm{m})\end{array}$ & $\begin{array}{l}\text { Li lixiviado } \\
(\% \mathrm{~m} / \mathrm{m})\end{array}$ \\
\hline \multirow{5}{*}{$\mathrm{H}_{2} \mathrm{SO}_{4}+\mathrm{H}_{2} \mathrm{O}_{2}$} & 1 & 42.5 & 40.0 \\
\hline & 2 & 79.0 & 77.0 \\
\hline & 2.5 & 88.5 & 86.0 \\
\hline & 3 & 92.0 & 90.5 \\
\hline & 4 & 92.2 & 90.5 \\
\hline \multirow{5}{*}{$\mathrm{HCl}+\mathrm{H}_{2} \mathrm{O}_{2}$} & 1 & 54.0 & 52.0 \\
\hline & 2 & 83.0 & 81.0 \\
\hline & 2.5 & 95.0 & 96.0 \\
\hline & 3 & 99.0 & 99.5 \\
\hline & 4 & 98.6 & 99.5 \\
\hline \multirow{5}{*}{$\mathrm{HF}+\mathrm{H}_{2} \mathrm{O}_{2}$} & 1 & 57.0 & 55.0 \\
\hline & 2 & 85.0 & 83.0 \\
\hline & 2.5 & 95.5 & 95.0 \\
\hline & 3 & 98.0 & 97.0 \\
\hline & 4 & 97.5 & 96.5 \\
\hline \multirow{5}{*}{$\mathrm{HCOOH}+\mathrm{H}_{2} \mathrm{O}$} & 1 & 39.0 & 37.0 \\
\hline & 2 & 76.0 & 75.5 \\
\hline & 2.5 & 83.0 & 80.0 \\
\hline & 3 & 85.0 & 83.0 \\
\hline & 4 & 85.5 & 83.0 \\
\hline
\end{tabular}

de excesso de $\mathrm{HF}$ devido à formação do composto $\mathrm{LiHF}_{2}{ }^{19,20} \mathrm{O}$ ácido fórmico, apesar de seu caráter redutor, foi o de pior desempenho entre todos.

A Tabela 3 apresenta as concentrações relativas das espécies lixiviadas (após adição das águas de lavagem ao lixiviado). As soluções têm cor avermelhada devido ao íon $\left[\mathrm{Co}\left(\mathrm{H}_{2} \mathrm{O}\right)_{6}\right]^{2+}$, exceto no caso do ácido fórmico, cuja cor é azul devido ao íon $\mathrm{Co}^{2+} .{ }^{30}$ Afora cobalto e lítio, os outros elementos identificados são alumínio, níquel, cálcio e cobre $\left(<1 \mathrm{~g} \mathrm{~L}^{-1}\right)$. Isso explica o precipitado formado quando se ajusta o $\mathrm{pH}$ antes da precipitação do lítio. As concentrações mostradas na Tabela 3 variaram principalmente em função do rendimento da lixiviação, pois a quantidade de água usada na lavagem foi muito parecida em todos os casos. A presença do níquel sugere uma substituição parcial do cobalto por este elemento no óxido duplo com lítio. ${ }^{6,8,11,12,16}$

\section{Análise do resíduo insolúvel da lixiviação}

A quantidade de resíduo insolúvel (Tabela 4) aumentou na ordem: $\mathrm{HCl}<\mathrm{H}_{2} \mathrm{SO}_{4}<\mathrm{HF}<\mathrm{HCOOH}$. Se levarmos em conta que o carbono seria o resíduo insolúvel esperado caso os metais fossem totalmente lixiviados $\left(\sim 310 \mathrm{mg} \mathrm{g}^{-1}\right)$, os pequenos aumentos verificados para os ácidos fortes e o fluorídrico decorrem da presença de cobalto e lítio não lixiviados. Isso se verifica de forma mais intensa para o ácido fórmico por conta de sua menor eficiência de lixiviação (Tabela 2).

Após calcinação, resultou uma cinza de cor azul decorrente da presença de cobalto. Tal como esperado, a massa de cinza aumentou na ordem $\mathrm{HCl}<\mathrm{H}_{2} \mathrm{SO}_{4}<\mathrm{HF}<\mathrm{HCOOH}$. A massa perdida se situou em $320 \pm 10 \mathrm{mg}$, o que concorda com a massa de carbono presente na massa de componentes eletroativos processada (Tabela 1).
Tabela 3. Concentrações típicas de metais nos lixiviados ( $\mathrm{t}=3 \mathrm{~h}$ )

\begin{tabular}{lcccccc}
\hline Lixiviante & $\begin{array}{c}\mathrm{Co}(\mathrm{II}) \\
\left(\mathrm{g} \mathrm{L}^{-1}\right)\end{array}$ & $\begin{array}{c}\mathrm{Li}^{+} \\
\left(\mathrm{g} \mathrm{L}^{-1}\right)\end{array}$ & $\begin{array}{c}\mathrm{Ni}(\mathrm{II}) \\
\left(\mathrm{g} \mathrm{L}^{-1}\right)\end{array}$ & $\begin{array}{c}\mathrm{Al}(\mathrm{III}) \\
\left(\mathrm{mg} \mathrm{L}^{-1}\right)\end{array}$ & $\begin{array}{c}\mathrm{Ca}(\mathrm{II}) \\
\left(\mathrm{mg} \mathrm{L}^{-1}\right)\end{array}$ & $\begin{array}{c}\mathrm{Cu}(\mathrm{II}) \\
\left(\mathrm{mg} \mathrm{L}^{-1}\right)\end{array}$ \\
\hline $\mathrm{H}_{2} \mathrm{SO}_{4}+\mathrm{H}_{2} \mathrm{O}_{2}$ & 17.9 & 5.3 & 0.9 & 50 & 20 & 30 \\
$\mathrm{HCl}+\mathrm{H}_{2} \mathrm{O}_{2}$ & 19.6 & 6.0 & 1.1 & 50 & 20 & 45 \\
$\mathrm{HF}+\mathrm{H}_{2} \mathrm{O}_{2}$ & 19.1 & 5.7 & 1.0 & 45 & n.d. & 30 \\
$\mathrm{HCOOH}+\mathrm{H}_{2} \mathrm{O}$ & 17.1 & 4.9 & 0.9 & 45 & 15 & n.d. \\
\hline
\end{tabular}

n.d. - não detectado.

Tabela 4. Massa de resíduo insolúvel após lixiviação de componentes eletroativos de baterias íon-lítio por $3 \mathrm{~h}$

\begin{tabular}{cc}
\hline Lixiviante & Massa de insolúveis $\left(\mathrm{mg} \mathrm{g}^{-1}\right)$ \\
\hline $\mathrm{H}_{2} \mathrm{SO}_{4}+\mathrm{H}_{2} \mathrm{O}_{2}$ & 370 \\
$\mathrm{HCl}+\mathrm{H}_{2} \mathrm{O}_{2}$ & 320 \\
$\mathrm{HF}+\mathrm{H}_{2} \mathrm{O}_{2}$ & 345 \\
$\mathrm{HCOOH}+\mathrm{H}_{2} \mathrm{O}$ & 415 \\
\hline
\end{tabular}

\section{Extração líquido-líquido do cobalto}

A Figura 3 apresenta as curvas de extração do $\mathrm{Co}$ (II) por D2EHPA em função do $\mathrm{pH}$ do lixiviado. A acidez tem papel marcante na extração do Co(II) por esse extratante. A fase orgânica somente começou a ficar azul (Figura 2) em pH a partir de 4. Mais de $99.5 \% \mathrm{~m} / \mathrm{m}$ do elemento foi extraído a partir de $\mathrm{pH} 5$. O $\mathrm{Ni}(\mathrm{II})$ praticamente não foi extraído $(<0.5 \%)$; de fato, a ordem de extração preferencial do $\mathrm{Co}(\mathrm{II})$ sobre $\mathrm{Ni}(\mathrm{II})$ é conhecida na literatura. ${ }^{10,25}$ Os traços de $\mathrm{Cu}$ (II) existentes nos lixiviados também foram extraídos juntamente com o cobalto. Assim, esse elemento pode se constituir num interferente caso presente no lixiviado em concentrações consideráveis. Isso pode exigir uma etapa prévia de remoção deste elemento por extração por extratantes do tipo oxima, altamente seletivos para $\mathrm{Cu}$ (II) em meio mais ácido ${ }^{31-33}$ do que para a extração do $\operatorname{Co}(\mathrm{II})$.

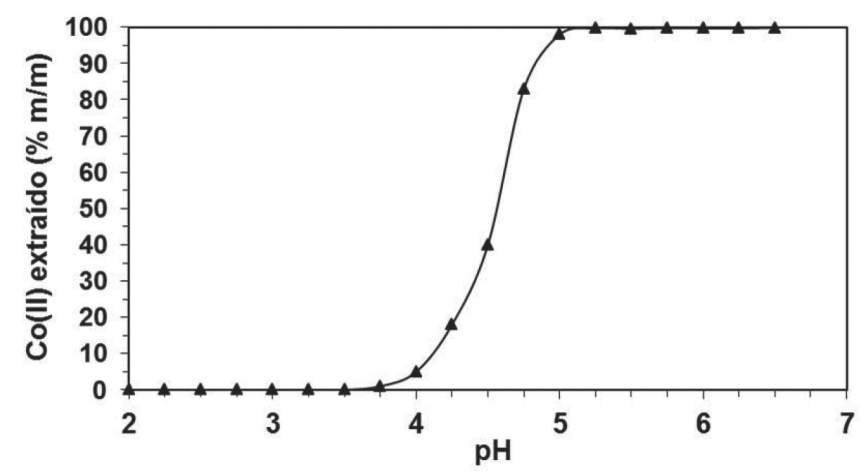

Figura 3. Influência do $\mathrm{pH}$ do lixiviado na extração do Co(II) por D2EHPA $16 \%$ vol. em $n$-hexano $\left(25^{\circ} \mathrm{C}, \mathrm{A} / \mathrm{O}=1 \mathrm{v} / \mathrm{v}\right.$, um estágio $)$

A extração do Co(II) segue a reação: ${ }^{34}$

$\mathrm{Co}^{2+}{ }_{\text {(aq.) }}+(\mathrm{HD})_{2 \text { (org.) }} \rightleftarrows \mathrm{Co}(\mathrm{D})_{2 \text { (org.) }}+2 \mathrm{H}_{\text {(aq.) }}^{+}(\mathrm{HD}=\mathrm{D} 2 \mathrm{EHPA})(9)$

Uma solução de D2EHPA $16 \%$ vol. em n-hexano foi suficiente para realização da extração em um único estágio (Figura 4). Um resultado decorrente da reação 9 é o aumento da acidez do rafinado. Os dados experimentais indicam uma acidez mais elevada $(\mathrm{pH} \sim 4)$ em relação àquela do lixiviado quando o $\mathrm{pH}$ foi ajustado para $\sim 5$.

A remoção do cobalto da fase orgânica foi conduzida com solução 


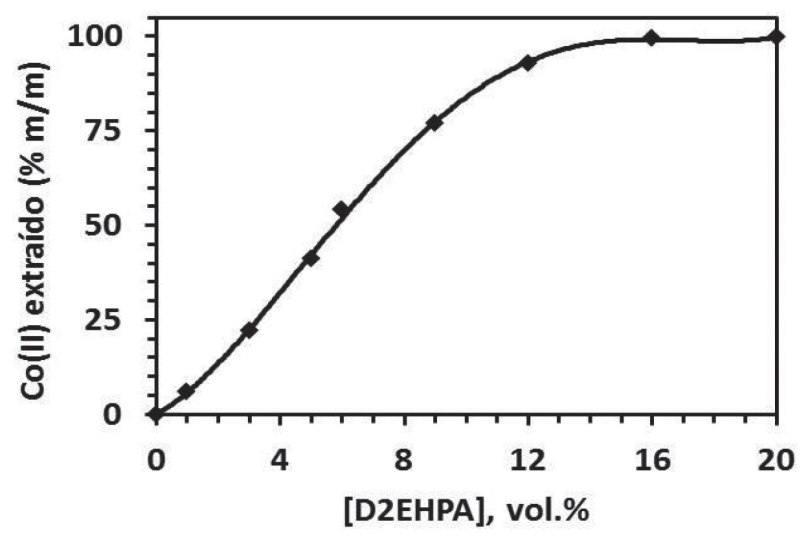

Figura 4. Influência da concentração de D2EHPA em n-hexano na extração do $\mathrm{Co}(\mathrm{II})$ em $\mathrm{pH} 5\left(25^{\circ} \mathrm{C}, \mathrm{A} / \mathrm{O}=1 \mathrm{v} / \mathrm{v}\right)$

diluída do ácido do lixiviante (Figura 5). Co(II) foi facilmente removido (>99.5\%) em um estágio, sendo que os ácidos fortes exigiram concentrações mais baixas (1-2 $\left.\mathrm{mol} \mathrm{L}^{-1}\right)$ do que os ácidos fracos (4-5 mol L $\left.{ }^{-1}\right)$. Concentrações mais elevadas devem ser evitadas para que não ocorra emulsificação.

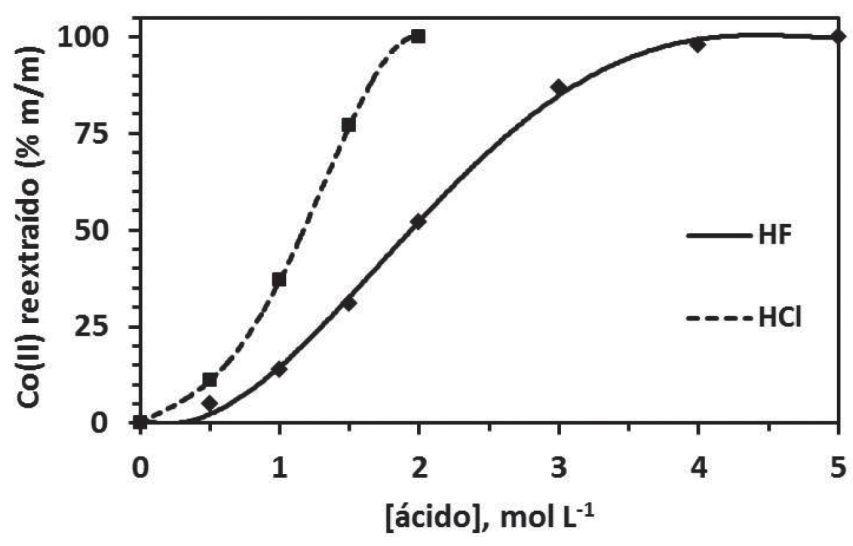

Figura 5. Exemplo da influência da natureza do ácido de reextração (forte) fraco) na remoção do $\mathrm{Co}(\mathrm{II})$ da fase orgânica $\left(\mathrm{A} / \mathrm{O}=1 \mathrm{v} / \mathrm{v}, 25^{\circ} \mathrm{C}\right.$, um estágio $)$

\section{Precipitação do lítio}

A Tabela 5 apresenta os dados comparativos aos dois métodos de precipitação testados. A base foi a determinação do lítio remanescente em solução, confrontando os resultados com a concentração nos lixiviados de origem (Tabela 3). Independentemente do ácido usado na lixívia, a precipitação do lítio como fosfato é mais efetiva por conta de sua menor solubilidade molar em relação ao carbonato. Mesmo este precipitado a $\sim 100{ }^{\circ} \mathrm{C}$ teve uma recuperação de lítio inferior à do fosfato à temperatura do laboratório, apesar da lixiviação desse metal alcalino ter variado com o ácido (Tabelas 2 e 3). De qualquer modo, os rendimentos verificados são bastante elevados; a vantagem de isolar o lítio como carbonato reside na labilidade deste, sendo facilmente convertido em outros sais por simples adição do ácido correspondente, sendo o carbonato eliminado como $\mathrm{CO}_{2} \cdot{ }^{19,30} \mathrm{Os}$ dados de FRX mostram, como esperado, que o cálcio é o principal contaminante $(0.2 \% \mathrm{~m} / \mathrm{m}$, visto que este elemento também precipita como carbonato ou fosfato.

A solução final contém, basicamente, o sal de sódio do ácido lixiviante. Mediante ajuste do $\mathrm{pH}$ correspondente à solução saturada do sal ( $\mathrm{NaCl}, \mathrm{Na}_{2} \mathrm{SO}_{4}, \mathrm{HCOONa}$ ou $\mathrm{NaF}$ ), seguido de evaporação lenta, é possível isolar tais sais com pureza elevada, ${ }^{23}$ reduzindo com isso a geração de resíduos finais.
Tabela 5. Recuperação média do lítio mediante precipitação de carbonatos ou fosfatos nos diversos rafinados após extração de Co(II) com D2EHPA

\begin{tabular}{lcc}
\hline Lixiviante & $\begin{array}{r}\% \mathrm{~m} / \mathrm{m} \mathrm{Li} \mathrm{recuperado} \\
\text { como } \mathrm{Li}_{2} \mathrm{CO}_{3}\end{array}$ & $\begin{array}{r}\% \mathrm{~m} / \mathrm{m} \mathrm{Li} \mathrm{recuperado} \\
\text { como } \mathrm{Li}_{3} \mathrm{PO}_{4}\end{array}$ \\
\hline $\mathrm{H}_{2} \mathrm{SO}_{4}+\mathrm{H}_{2} \mathrm{O}_{2}$ & 95.0 & 99.7 \\
$\mathrm{HCl}+\mathrm{H}_{2} \mathrm{O}_{2}$ & 95.5 & 99.8 \\
$\mathrm{HF}+\mathrm{H}_{2} \mathrm{O}_{2}$ & 95.3 & 99.6 \\
$\mathrm{HCOOH}+\mathrm{H}_{2} \mathrm{O}$ & 94.9 & 99.6 \\
\hline
\end{tabular}

\section{CONCLUSÕES}

A lixiviação de lítio e de cobalto de baterias de íon-lítio em meio de ácido fluorídrico mostrou desempenho comparável aos dos ácidos fortes tradicionalmente estudados na literatura $\left(\mathrm{HCl} \mathrm{e} \mathrm{H}_{2} \mathrm{SO}_{4}\right)$, mas o ácido fórmico, apesar de seu caráter redutor, teve rendimento cerca de $15 \%$ inferior aos dos demais ácidos. $\mathrm{O}_{2} \mathrm{O}_{2}$ é essencial para a boa condução do processo, sendo um melhor redutor do $\mathrm{Co}$ (III) do que o ácido fórmico. A fração insolúvel após as lixiviações é majoritariamente composta por carbono (grafita) oriunda do catodo das baterias e dos metais não lixiviados.

A extraçâo do Co(II) por D2EHPA é possível em pH fracamente ácido ( 5) sem interferência do níquel e do lítio, mas o cobre pode se constituir num elemento interferente caso presente no lixiviado em concentrações consideráveis. A precipitação do lítio se mostrou mais efeitva e com menor consumo energético na forma de fosfato, embora o carbonato seja um sal mais versátil como ponto de partida para a produção de outros compostos de lítio. Um pré-requisito para uma boa separação do lítio é o ajuste do $\mathrm{pH}$ de modo a remover metais como níquel e alumínio antes de sua precipitação.

\section{AGRADECIMENTOS}

Ao CNPq, à CAPES e à FAPERJ pelo apoio financeiro. Ao Centro de Tecnologia Mineral (CETEM) pelas análises de difração de raios-X. Ao Instituto de Engenharia Nuclear (IEN) pelas análises de fluorescência de raios-X.

\section{REFERÊNCIAS}

1. Niu, Z.; Zou, Y.; Xin, B.; Cher, S.; Liu, C.; Li, Y.; Chemosphere 2014, 109, 92.

2. Zhang, T.; He, Y.; Ge, L.; Fu, R.; Zhang, X.; Huang, Y.; J. Power Sources 2013, 240, 766.

3. Kang, J. G.; Sohn, G.; Chang, H.; Senanayake, G.; Shin, S. M.; Hydrometallurgy 2010, 100, 168.

4. Kang, J. G.; Sohn, G.; Chang, H.; Senanayake, G.; Shin, S. M.; Advanced Power Technology 2010, 21, 175.

5. Chen, L.; Tang, X.; Zhang, Y.; Li, L.; Zeng, Z.; Zhang, Y.; Hydrometallurgy 2011, 180, 80.

6. Gratz, E.; Sa, Q.; Apelian, D.; Wang, Y. J.; J. Power Sources 2014, 262, 255.

7. Meshram, P.; Pandey, B. D.; Mankhand, T. R.; Chem. Eng. J. 2015, 281, 418.

8. Jha, M. K.; Kumari, A.; Jha, A. K.; Kumar, V.; Hart, J.; Pandey, B. D.; Waste Manage. 2013, 33, 1890.

9. Maschler, T.G.; Friedrich, B.; Weyhe, R.; Heegn, H.; Rutz, M.; J. Power Sources 2012, 207, 173.

10. Chen, X.; Chen, Y.; Zhou, T.; Liu, D.; Hu, H.; Fan, S.; Waste Manage. 2015, 38, 349.

11. Nayaka, G. P.; Manjanna, J.; Pai, K. V.; Vadavi, R.; Keny, S. J.; Tripathi, V. S.; Hydrometallurgy 2015, 151, 73. 
12. Bertuol, D. A.; Toniasso, C.; Jiménez, B. M.; Meili, L.; Dotto, G. L.; Tanabe, E. H.; Aguiar, M. L.; J. Power Sources 2015, 275, 627.

13. eWaste in Latin America: Statistical analysis and policy recommendations. United Nations University. UNU-IAS Institute for the Advanced Study of the Sustainability, New York, 2015.

14. Pranolo, Y.; Zhang, W.; Cheng, C. Y.; Hydrometallurgy 2010, 102, 374.

15. Lee, C. K.; Rhee, K. I. J.; Power Sources 2002, 109, 17.

16. Al-Thyabat, S.; Nakamura, T.; Shibata, E.; Iizuka, A.; Miner. Eng. 2013, $45,4$.

17. Joulié, M.; Laucournet, R.; Billy, E.; J. Power Sources 2014, 247, 551.

18. Zhang, X.; Cao, H.; Xie, Y.; Ning, P.; An, H.; You, H.; Nawaz, F.; Sep. Purif. Technol. 2015, 150, 186.

19. Lurie, J.; Handbook of Analytical Chemistry, $3^{\text {rd }}$ ed., Mir: Moscow, 1978, chap. 3, 6 and 10 .

20. Feigl, F.; Spot Tests in Inorganic Analysis, Elsevier: Amsterdam, 1958, chap. 3.

21. Lima, T. S.; Campos, P. C.; Afonso, J. C.; Hydrometallurgy 2005, 80, 211.

22. Pinheiro. A. A. S.; Lima, T. S.; Campos, P. C.; Afonso, J. C.; Hydrometallurgy 2004, 74, 77.

23. Ibiapina, V. F.; Florentino, U. S.; Afonso, J. C.; Gante, V.; Vianna, C. A.; Mantovano, J. L.; Quim. Nova 2018, 41, 176.
24. Liu, X.; Li, S.; Liu, Y.; Cao, Y.; Chin. J. Catal. 2015, 36, 1461.

25. Ritcey, G. M., Ashbrook, A. W.; Principles and Applications to Process Metallurgy (Part I) New York: Elsevier Science Publishers, 1984, 364 p.

26. Roine, A.; HSC Chemistry ${ }^{\circledR}$ ver. 6.1, Outotec Research Oy: Helsinki, 2010.

27. Borgstedt, H. U.; Guminski, C.; Metals in Liquid Alkali Metals. International Union of Pure and Applied Chemistry, Be to Os, Part I: Oxford University Press: Oxford, 1996.

28. Nazri, G. A.; Pistoia, O.; Lithium Batteries: Science and Technology, Kluwer Academic Publishers: Dordrecht, 2003.

29. Varela, F. H.; Huguenin, M.; Malta, R.; Torresi. M.; Quim. Nova 2002 , $25,287$.

30. Greenwood, N. N.; Earnshaw, A.; Chemistry of the Elements, $2^{\text {nd }}$ Ed., Elsevier Butterworth-Heinemann: London, 2010, chap.10.

31. Gotfryd, L., Pietek, G.; Physicochem. Probl. Miner. Process. 2013, 49 , 133.

32. Qiu, Y.; Yang, L.; Huang, S.; Ji, Z.; Li, Y.; Chin. J. Chem. Eng. 2017, 25, 760.

33. Sole, K. C.; Feather, A. M.; Cole, P. C.; Hydrometallurgy 2005, 78, 52.

34. Gouvea, L. R.; Morais, C. A.; Miner. Eng. 2010, 23, 492. 